\title{
Dimensionality and Hierarchical Structure of Disability Measurement
}

\author{
Yvonne J. J. M. van Boxel, MSc, Frits H. J. Roest, MSc, Michael P. Bergen, MD, PhD, \\ Henk J. Stam, MD, PhD
}

ABSTRACT. van Boxel YJJM, Roest FHJ, Bergen MP, Stam HJ. Dimensionality and hierarchical structure of disability measurement. Arch Phys Med Rehabil 1995;76:1152-5.

Since the D-code of the International Classification of Impairments, Disabilities, and Handicaps (ICIDH) in its full form has proven to be impractical, an instrument based on a selection of 28 items is used to measure disability in Dutch patients undergoing rehabilitation. The items are categorized into 5 domains of physical, activities of daily living (ADL), social, psychological, and communicative activity. Measurement is made on a 4-point scale ranging from 0 (not disabled) to 3 (severely disabled). As a result of the ordinal character of the rating, statistical and mathematical manipulations of the scores are complicated. The aim of this study was to obtain more insight in the dimensionality and hierarchical structure of the items, to overcome problems in comparing disability between items, between patients, and within patients between different moments in time. Mokken scale analysis of the disability scores from 1,967 rehabilitation inpatients showed that the 28 items constitute hierarchical scales. However, categorization of the items into the 5 original domains was not replicated. Five other scales or dimensions were investigated, measuring the level of extended ADL, extended psychological, fine motoric, work/leisure, and hearing/ seeing activity, respectively. The number of items per dimension ranges from 14 in the extended $A D L$ dimension to 2 each in the work/leisure and hearing/seeing dimensions. Although each disability item may be of importance in clinical case management, a reduced set of extended ADL items suffices to describe the disability level in this dimension for epidemiological research purposes. The other dimensions need further specification to provide reliable and sensitive measuring of disability.

(C) 1995 by the American Congress of Rehabilitation Medicine and the American Academy of Physical Medicine and Rehabilitation

$\mathrm{I}^{\mathrm{N}}$ N 1980, the World Health Organization developed the International Classification of Impairments, Disabilities, and Handicaps (ICIDH). ${ }^{1}$ The ICIDH is now used as a manual for classification of the consequences of disease in different medical specialities. Jiwa-Boerrigter and associates ${ }^{2}$ described the application of the ICIDH in the field of rehabilitation medicine. The disability or D-Code of the ICIDH, which describes the

From the Institute of Physical Medicine and Rehabilitation (Ms. van Boxel, Dr. Bergen, Dr. Stam) and the Center for Clinical Decision Sciences (Mr. Roest), Erasmus University Rotterdam, The Netherlands.

Submitted for publication December 6, 1994. Accepted in revised form May $17,1995$.

No commercial party having a direct or indirect interest in the results of the research supporting this article has or will confer a benefit upon the authors or upon any organization with which the authors are associated.

Reprint requests to Y. J. J. M. van Boxel, MSc, Department of Rehabilitation, University Hospital Rotterdam-Dijkzigt Dr. Molewaterplein 40, 3015 GD Rotterdam, The Netherlands.

(C) 1995 by the American Congress of Rehabilitation Medicine and the American Academy of Physical Medicine and Rehabilitation

$0003-9993 / 95 / 7612-3346 \$ 3.00 / 0$ restriction or inability to perform an activity in the manner or within the range considered normal, taking into account age, sex and culture, is most relevant in rehabilitation medicine. Disability cannot be confined to an appraisal of only one entity. ${ }^{3}$ As a result, disability measurement requires the construction of different rating scales, and the D-Code includes several activities. Since the D-Code in its full form has proven to be impractical, instruments have been developed that are based on a selection of disability items from the ICIDH.

Recently, an instrument based on 28 items from the ICIDH has been used to measure disability in Dutch patients undergoing rehabilitation. ${ }^{4}$ The 28 items are categorized into 5 domains (table 1): physical activity (10 items); activity in daily life (ADL, 4 items); social activity (5 items); psychological activity (4 items); and communication (5 items). A 4-point scale ranging from 0 (not disabled) to 3 (severely disabled) is used to rate the disability level (table 2$)^{5}$

Because the 4-point scale measures magnitude of disability without possessing equal intervals or absolute zeros, the scale is called ordinal in character. ${ }^{6}$ Each successive score does not necessarily represent an equal amount of change. A score of 3 means more disabled than a score of 2 and a score of 1 means more disabled than a score of 0 , but the difference between 3 and 2 is not necessarily equal to the difference between 1 and 0 . The score numbers imply equal intervals, but in reality the differences between scores are probably not equal. As a result, the scores cannot easily be totalled and averaged. Moreover, a total score can be composed of high scores on some items and low scores on others, as well as of consistently moderate scores on all items. As Barer and Murphy ${ }^{7}$ have reported on the Barthel Index, patients with different patterns of disability can achieve the same total score. As a result, one patient with a lower sum score for the physical items, for instance, may not automatically be diagnosed as less disabled in physical activity than another who has a higher score. Although the sum of ordinal scores appears to have meaning, all that is known is that the sum is greater, to some unknown degree, than any of the individual scores.

Because an ordinal scale is characterized by the absence of an absolute zero, the same score does not necessarily represent the same level of disability for all items. For instance, one patient who is moderately disabled (score 2) in climbing stairs may not automatically be diagnosed as equally disabled as another patient with a disability score 2 for walking.

As a result of the ordinal character of the 28 -item instrument, any conclusions from mathematical or statistical manipulations of the scores may be misleading. ${ }^{8}$ Comparing disability measurements between items, between patients, or within patients between different moments in time is complicated. These complications may be overcome if the items in the instrument can be combined to provide a hierarchical measure for a single dimension. The extent to which the items can be combined to provide information along one underlying dimension is called the dimensionality. ${ }^{9}$ The hierarchical structure of the items in the instrument is defined as the extent to which the items form 
hierarchical scales. Such a hierarchical item model assumes that each disability item reflects a certain level of difficulty. Patients who are little disabled may be unable to manage a relatively difficult activity but may manage less arduous activities. With increasing level of disability, patients are more likely to have difficulties managing relatively easy activities. Patients having difficulties with a relatively easy activity, however, will probably also be disabled in managing a more difficult one. This study investigated the dimensionality and the hierarchical structure of disabilities measured by using the 28 -item instrument based on the ICIDH.

\section{METHODS}

\section{Subjects}

Since 1988, the 28-item instrument has been used in the university hospital to rate the disability level of rehabilitation patients. During the years 1988 to $1990,1,967$ inpatients were treated in rehabilitation during hospitalization. The disability scores of these patients were analyzed in this study. A more detailed description of the study population will be published elsewhere. ${ }^{10}$

\section{Instruments}

To register the disability level of the patients, a standard form was used. For each patient the rehabilitation specialist completed the form at the moment of discharge from hospitalbased inpatient rehabilitation. A coding expert was responsible for the input of the encoded data in a computer registration system.

\section{Analysis}

To investigate the dimensionality and hierarchical structure of the disability items, Mokken scale analysis was performed using MSP, a computer program for Mokken scale analysis for polychotomous items. ${ }^{11-14}$ To scale persons and items hierarchically on a single dimension, MSP contains a bottom-up item selection procedure that starts by selecting the pair of items for which the scalability coefficient Loevinger's $H$ is significantly larger than 0 , and Loevinger's $H$ is the largest among the coefficients for all item pairs. Then a third item is selected that (1) correlates positively with the items already selected, (2) does not decrease the overall scalability coefficient Loevinger's $H$

Table 1: Twenty-Eight Items for Measuring Disability in Rehabilitation Patients

\begin{tabular}{lcc}
\hline $\begin{array}{c}\text { Physical activity } \\
\text { Transfer lying-sitting }\end{array}$ & $\begin{array}{c}\text { Daily life activity (ADL) } \\
\text { Feeding }\end{array}$ & $\begin{array}{c}\text { Social activity } \\
\text { Transport }\end{array}$ \\
$\begin{array}{cc}\text { Transfer sitting- } \\
\text { standing }\end{array}$ & $\begin{array}{c}\text { Using lavatory } \\
\text { Walking indoors }\end{array}$ & $\begin{array}{l}\text { Housing* } \\
\text { Employment }\end{array}$ \\
Walking outdoors & Clothing & $\begin{array}{l}\text { Family role } \\
\text { Climbing stairs }\end{array}$ \\
Reaching & & \\
Manipulating & & \\
Endurance & & \\
Bending & & \\
Lifting & & \\
Psychological activity & Communication \\
Orientation & Understanding speech & \\
Memory, attention & Talking & \\
Behavior, mood & Hearing & \\
Learning abilities & Seeing & \\
& Writing & \\
\hline
\end{tabular}

* Housing as a social activity includes all activities needed for practical access and use of the home.
Table 2: Four-point Scale Used for Disability Rating

\begin{tabular}{cc}
\hline Score & Description \\
\hline 0 & $\begin{array}{c}\text { The individual is able to perform the activity without difficulty, } \\
\text { with or without use of aids and appliances. } \\
\text { The individual is able to perform the activity with some } \\
\text { difficulty, with or without use of aids and appliances. }\end{array}$ \\
2 & $\begin{array}{c}\text { The individual is able to perform the activity with much } \\
\text { difficulty, with or without use of aids and appliances. }\end{array}$ \\
3 & $\begin{array}{c}\text { The individual cannot perform the activity, even with use of } \\
\text { aids and appliances. }\end{array}$ \\
\hline
\end{tabular}

below 0 , and (3) has an item scalability coefficient $H_{i}$ that is larger than a threshold value. The program continues to select items as long as items are available that satisfy the three conditions. $^{15}$ The Loevinger's $\mathrm{H}$ coefficient is a measure for the strength of a scale. Scales having an $\mathrm{H}$ coefficient between .30 and .40 and between .40 and .50 are considered weak and moderate hierarchical scales, respectively. Scales with an $\mathrm{H}$ coefficient of .50 or higher are strong hierarchical scales. The item coefficient $\mathrm{H}_{\mathrm{i}}$ is a measure for the fit of an item in a scale. In this study, analysis was performed using a threshold value .30 for $\mathrm{H}_{\mathrm{i}}$. Reliability of the scales was assessed by coefficient rho $(\rho)$. Because the disability rating was on an ordinal scale, correlations between scores were investigated by calculating the Spearman rank correlation coefficients using the statistical package SPSS/PC. ${ }^{16}$

\section{RESULTS}

Table 3 shows that the original 5 domains had satisfactory hierarchical scale characteristics. All Loevinger's H coefficients were above .30 and the reliability represented by $\rho$ coefficient was high. The ADL and psychological domains even constituted strong hierarchical scales. However, the five domains were highly correlated (table 4 ), resulting in a high percentage of the information in the scales being redundant.

The Mokken procedure investigated 5 dimensions among the 28 disability items (fig 1). The first dimension or scale consisted of most of the original physical, ADL, and social items and could be considered as a measure of extended ADL functioning. The second scale could be interpreted as an extended psychological dimension, consisting of all original psychological activities completed with two of the original communicative activities. The third scale was characterized by fine motoric activities, such as manipulating and writing. The remaining two dimensions represented more or less isolated aspects of disability, such as the disability to perform work and leisure activities, and the disability to hear and see. The original categorization of the items into the five domains of physical, ADL, social, psychological, and communicative disability was not replicated.

Table 5 shows that the hierarchical scale characteristics of the extended ADL, extended psychological, and fine motoric dimensions were satisfactory.

The figure summarizes the disability on the 28 items of the 1,967 rehabilitation inpatients treated in 1988, 1989, and 1990. Some items from the extended ADL dimension had been rated approximately in the same way. For instance, about $62 \%$ of the

\begin{tabular}{lcc}
\multicolumn{1}{c}{ Table 3: Hierarchical Structure of the Original Five Disability Domains } \\
\hline \multicolumn{1}{c}{ Domain } & Loevinger's H & $\rho$ Coefficient \\
\hline Physical activity & .51 & .91 \\
ADL & .74 & .95 \\
Social activity & .39 & .80 \\
Psychological activity & .75 & .94 \\
Communication & .40 & .83 \\
\hline
\end{tabular}


Table 4: Correlations Between the Original Five Disability Domains

\begin{tabular}{lcrrcc}
\hline & Physical & ADL & Social & Psychological & Communication \\
\hline Physical & 1.00 & & & & \\
ADL & .83 & 1.00 & & & \\
Social & .71 & .67 & 1.00 & & \\
Psychological & .42 & .48 & .45 & 1.00 & \\
Communication & .48 & .52 & .41 & .61 & 1.00 \\
\hline
\end{tabular}

patients were not disabled or only little disabled in "transfer sitting-standing," "using lavatory," "bathing," and "clothing." Moreover, about half of the patients had no or few problems in "walking indoors" and "housing" and only $35 \%$ of the patients could "walk outdoors" and "climb stairs" without moderate or severe difficulties. Because items with the same distribution of scores along one dimension can be considered to have the same difficulty, it was investigated whether some extended ADL items were redundant, ie, provided no additional information about the patient's disability level in extended ADL functioning. The items " using lavatory," "bathing," "clothing," "housing," and "walking outdoors" were excluded from analysis because of a lower scalability coefficient $H_{i}$ than the items "transfer sitting-standing," "walking indoors," and "climbing stairs," respectively. Mokken analysis showed that the hierarchical characteristics of the reduced extended ADL scale remained good (table 6). Since the other four dimensions consisted of relatively small numbers of items compared with the 14 items in the extended ADL dimension, no analyses were conducted to study whether some of these items were redundant.

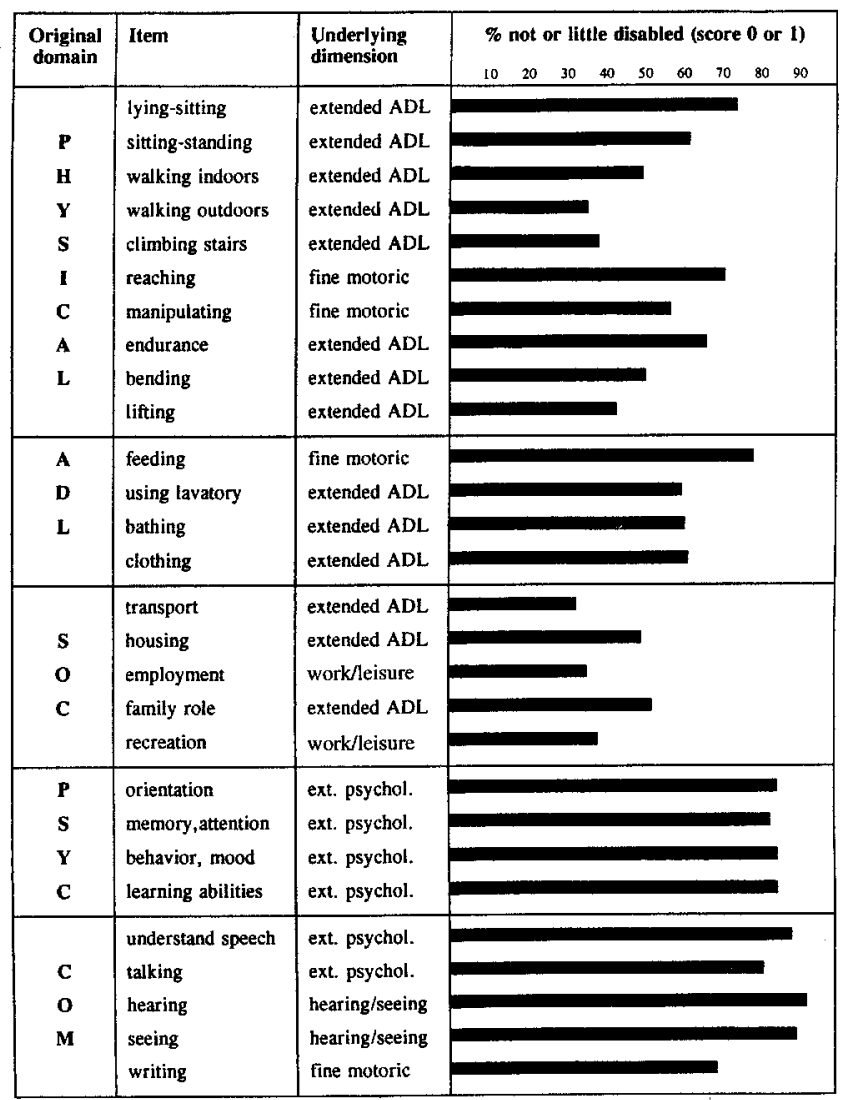

Fig 1. Dimensionality and measurement of disability in 1,967 rehabilitation inpatients.
Table 5: Hierarchical Structure of the Three Main Disability Dimensions After Scale Analysis

\begin{tabular}{lcc}
\hline \multicolumn{1}{c}{ Dimension } & Loevinger's H & $\rho$ Coefficient \\
\hline Extended ADL functioning & .57 & .96 \\
Extended psychological functioning & .60 & .93 \\
Fine motoric functioning & .47 & .85 \\
\hline
\end{tabular}

\section{DISCUSSION}

The results of this study showed that the original five domains of physical, ADL, social, psychological, and communicative disability in the 28 -item rating instrument constitute satisfactory but correlating hierarchical scales. The hierarchical character implies that the occurrence of disabilities can be ordered consistently within a domain. For instance, patients with disabilities in physical activity start having problems with walking outdoors, representing a relatively difficult activity (65\% of the patients were moderately or severely disabled in walking outdoors), followed by having problems walking indoors. Eventually, severely disabled patients may have trouble with the transfer lying-sitting, which represents a relatively easy activity ( $20 \%$ of the patients had moderate or severe problems in transfer lyingsitting). On the other hand, patients who are disabled in the transfer lying-sitting are probably also disabled in walking.

Contrary to the significant differences in difficulty among the 10 physical activities in the instrument, the difficulty level differs only little among items within the ADL, social, psychological, and communicative domains, respectively. For instance, $86 \%$ of the patients were not or little disabled in memory, representing the most difficult psychological activity. The percentage of not or only little disabled patients in the other three, less difficult, psychological activities is $88 \%$ and, thus, only a little higher. As a result, the instrument enables ordering of the psychological items only at a small interval. Measuring of psychological disability is less sensitive to change than measuring physical activity. Mokken analysis showed that the 28-item instrument based on the ICIDH enables evaluation of disability along three main dimensions, which differ from the original five disability domains. The most important underlying dimension is extended ADL functioning, which includes 14 of the 28 items and, thus, is somewhat overrepresented in the instrument. Although each disability item may be of importance in clinical case management, a reduced set of items suffices to describe the level of extended ADL functioning in patients for epidemiological research purposes. The items "using lavatory," "bathing," "clothing," "housing," and "walking outdoors" can be excluded from statistical analysis in studying groups of patients.

The extended psychological dimension is sufficiently represented by 6 items, although the sensitivity of this measurement is low. The number of items representing fine motoric functioning and, especially, work/leisure activity and hearing/seeing ability should be extended to rate the disability in these dimensions in a reliable way. Before starting further research on the specification of these dimensions, however, it has to be considered whether reliable information on these dimensions is desirable, ie, is needed to achieve the purposes of data collection. As de Kleijn-Vrankrijker ${ }^{17}$ reported on the application of the

Table 6: Hierarchical Structure of the Extended ADL Dimension Before and After Reduction

\begin{tabular}{lcc}
\hline \multicolumn{1}{c}{ Dimension } & Loevinger's H & $\rho$ Coefficient \\
\hline Extended ADL (14 items) & .57 & .96 \\
Reduced extended ADL (9 iterns) & .59 & .94 \\
\hline
\end{tabular}


ICIDH in interview surveys, the purposes for registration of rehabilitation patients define the dimensions on which data have to be collected. In The Netherlands, registration purposes are formulated for both individual case management and for epidemiological studies. Rehabilitation specialists and researchers together have to decide which data are needed to achieve these aims.

\section{References}

1. World Health Organization. International classification of impairments, disabilities and handicaps (ICIDH): a manual of classification relating to the consequences of disease. Geneva, Switzerland: WHO, 1980.

2. Jiwa-Boerrigter H, van Engelen HGM, Lankhorst GJ. Application of the ICIDH in rehabilitation medicine. International Disability Studies 1990; 12:17-9.

3. Feinstein AR, Josephy BR, Wells CK. Scientific and clinical problems in indexes of functional disability. Ann Intern Med 1986; 105:413-20.

4. van Boxel YJJM, Bergen MP, Stam HJ. Registration of rehabilitation patients in the Netherlands: practical experiences (in Dutch). Medisch Contact 1994;49:841-2.

5. van den Berg JP, Lankhorst GJ. Inter-rater and intra-rater reliability of disability ratings based on the modified D-Code of the ICIDH. Int Disabil Stud 1990; 12:20-1.

6. Collin C. Scales and scaling techniques used in measurement in rehabilitation medicine. Clin Rehabil 1992;6:91-6.
7. Barer DH, Murphy JJ. Scaling the Barthel: a 10-point hierarchical version of the activities of daily living index for use with stroke patients. Clin Rehabil 1993; 7:271-7.

8. Merbitz C, Morris J, Jeffrey CG. Ordinal scales and foundations of misinference. Arch Phys Med Rehabil 1989;70:308-12.

9. Wright $\mathrm{BD}$, Linacre JM. Observations are always ordinal; measurements, however, must be interval. Arch Phys Med Rehabil 1989; 70:857-60.

10. van Boxel YJJM, Bergen MP, Roest FHJ, Stam HJ. Characteristics of patients from hospital-based inpatient rehabilitation in The Netherlands. Int J Rehabil Res 1995; in press.

11. Mokken RJ. A theory and procedure of scale analysis. The Hague, the Netherlands: Mouton, 1971.

12. Mokken RJ, Lewis C, Sijtsma K. Rejoinder to the Mokken scale: a critical discussion. Appl Psychol Measure 1986;10:279-85.

13. Debets P, Brouwer E. User's manual MSP: a program for Mokken Scale Analysis for polychotomous items; version 1.50. Groningen, the Netherlands: ProGRAMMA, 1987.

14. Sijtsma K, Debets P, Molenaar IW. Mokken scale analysis for polychotomous items: theory, a computer program and an empirical application. Qual Quant 1990;24:173-88.

15. Meijer RR, Sijtsma K, Smid NG. Theoretical and empirical comparison of the Mokken and the Rasch approach to IRT. Appl Psychol Measure 1990; 14:283-98.

16. Noruis M. SPSS/PC+ advanced statistics 4.0. Chicago: SPSS Inc., 1990.

17. de Kleijn-de Vrankrijker MW. Application of the ICIDH in interview surveys. Int Rehabil Med 1986;8:23-5. 